\title{
Salivary Interleukin-6 and C-Reactive Protein/Mean Platelet Volume Ratio in the Diagnosis of Late-Onset Neonatal Pneumonia
}

\author{
Ahmed Omran $\mathbb{D}^{1},{ }^{1}$ Yasmin Ali, ${ }^{1}$ Mohamed Osama Abdalla $\mathbb{D}^{2},{ }^{2}$ Sonya El-Sharkawy, ${ }^{3}$ \\ Ahmed R. Rezk $\left(1,{ }^{4}\right.$ and Abdelmoneim Khashana $\mathbb{(}^{1}$ \\ ${ }^{1}$ Department of Pediatrics \& Neonatology, Faculty of Medicine, Suez Canal University, Ismailia, Egypt \\ ${ }^{2}$ Department of Clinical Pathology, Faculty of Medicine, Suez Canal University, Ismailia, Egypt \\ ${ }^{3}$ Department of Pediatrics \& Neonatology, Faculty of Medicine, Port Said University, Port Said, Egypt \\ ${ }^{4}$ Department of Pediatrics, Ain Shams University, Cairo, Egypt
}

Correspondence should be addressed to Ahmed Omran; agomran1@yahoo.com

Received 28 August 2021; Revised 26 September 2021; Accepted 27 September 2021; Published 18 October 2021

Academic Editor: Syed Sameer Aga

Copyright (c) 2021 Ahmed Omran et al. This is an open access article distributed under the Creative Commons Attribution License, which permits unrestricted use, distribution, and reproduction in any medium, provided the original work is properly cited.

\begin{abstract}
Neonatal pneumonia is a serious respiratory infectious disease with a high rate of case fatality in developing countries. Salivary cytokines could serve as interesting noninvasive markers in the diagnosis of neonatal pneumonia. The aim was to assess the diagnostic role of salivary and serum interleukin-6 (IL-6), C-reactive protein/mean platelet volume (CRP/MPV) ratio, and the combination of these markers in the diagnosis of late-onset neonatal pneumonia in full-term neonates. Seventy full-term neonates, 35 with late-onset neonatal pneumonia and 35 controls, were enrolled in this prospective case-control study. Complete blood count (CBC), salivary and serum IL-6, and CRP concentrations were measured for all the study subjects. The sensitivity, specificity, positive predictive value, and negative predictive value of salivary IL-6, serum IL-6, and CRP/MPV ratio for the diagnosis of late-onset neonatal pneumonia were determined. At the cutoff point of $>34 \mathrm{pg} / \mathrm{ml}$, salivary IL-6 showed $82.86 \%$ sensitivity and $91.43 \%$ specificity. CRP/MPV ratio showed a sensitivity of $97.14 \%$ and specificity of $85.71 \%$ at a cutoff value $>0.88$. The combination of salivary IL- 6 and CRP/MPV ratio improved the sensitivity and specificity to $100 \%$. The current study shows for the first time that both salivary IL-6 and CRP/MPV ratio are suitable markers for the diagnosis of late-onset neonatal pneumonia in full-term neonates.
\end{abstract}

\section{Introduction}

Neonatal pneumonia remains a major global health burden and contributes to annual deaths of nearly one million neonates that represent $10 \%$ of global child mortality [1]. Although diagnosis of neonatal pneumonia could be a challenging task, accurate and very early diagnosis is essential for proper treatment and avoids complications.

Interleukin-6 (IL-6) is a pleiotropic proinflammatory cytokine produced by a variety cells in response to infection [2]. Blood IL-6 is an early sensitive marker of neonatal bacterial infection and one of the most studied cytokines in the diagnosis of infection in neonates [3-12].
In early stages of pneumonia, alveolar macrophages produce proinflammatory cytokines. The main cytokines produced are tumor necrosis factor- $\alpha$ and IL-6, and their systemic and bronchoalveolar levels increase subsequently during the disease course $[13,14]$. Blood IL-6 is a useful marker in determining the severity of the lung injury and inflammatory response in children with pneumonia, with higher levels correlating with disease severity and early mortality [15-17].

Saliva represents an excellent noninvasive, easy to perform, and patient-friendly biofluid for the screening of neonatal infections [18-20]. Salivary analysis is a potentially novel tool for the diagnosis of pneumonia in children [21, 
22]. The salivary IL-6 level was significantly higher in children with pneumonia compared to healthy controls [22].

Blood C-reactive protein (CRP) level and mean platelet volume (MPV) can be used for the diagnosis of neonatal pneumonia [19]. MPV is a surrogate marker of platelet activation and is associated with neonatal infections and other inflammatory and infectious diseases [19, 20, 23-32]. In pediatrics, the CRP/MPV ratio can be used as a marker for the differential diagnosis between bacterial and viral pneumonia as well as the prediction of complications [33].

To the best of our knowledge, this is the first study to evaluate the applicability of salivary IL-6 and CRP/MPV ratio as diagnostic markers in full-term neonates with lateonset pneumonia.

\section{Materials and Methods}

2.1. Design and Patients. The present study is a prospective case-control study. Subjects included 35 full-term neonates diagnosed with late-onset pneumonia and 35 controls. The cases of the present study were recruited from the neonatal intensive care unit (NICU) of Suez Canal University Hospitals, Ismailia, Egypt, for the duration from January 2018 to January 2019. The protocol was approved by the Faculty of Medicine Institutional Review and Research Ethics Boards.

Inclusion criteria of cases were neonates with $\geq 37$ weeks of gestational age, birth weight of $\geq 2.5 \mathrm{~kg}$ for both females and males, and age of 7 to 28 days of life admitted with clinical features of late-onset neonatal pneumonia. The definitive diagnosis of neonatal pneumonia was based on the presence of clinical manifestations in the form of various degrees of respiratory distress, intercostal or subcostal retractions, grunting, cough, and associated chest X-ray suggestive of pneumonia (includes lobar or segmental consolidation, diffuse haziness or granularity, nodular or coarse patchy infiltrates, and air bronchogram signs) [34].

Exclusion criteria were neonates with sepsis and other inflammatory conditions, preterm, low birth weight, major congenital anomalies, and antibiotics administration before admission.

The control group included matched age and sex neonates with no clinical features or risk factors for infection and followed up in our hospital for noninfectious neonatal jaundice.

2.2. Saliva Collection. We collected the saliva at $7 \mathrm{am}$, as salivary cytokines have independent diurnal rhythms [35]. Saliva collection was performed as mentioned in previously published work $[19,20,36]$. To avoid contamination by milk, samples were collected 1 hour before feeding. Collected samples were put immediately in polypropylene vials and stored at $-20^{\circ} \mathrm{C}$ until batch analysis.

2.3. Laboratory Workup. Two ml of venous blood was collected and separated in plain and EDTA tubes. Complete blood count (CBC) was done with a Sysmex XN-550 Hematology Analyzer (Sysmex Corp., Kobe, Japan). To avoid false increase of the MPV value due to platelet swelling, CBC was done within less than 60 minutes of sampling. Serum CRP was quantified using the Cobas 6000 analyzer (Roche, Mannheim, Germany). The serum IL-6 level was assessed by an enzyme-linked immunosorbent assay (ELISA) commercial kit (ab46042, Abcam, UK). Salivary samples were centrifuged for $4000 \mathrm{rpm}$ for 10 minutes. Supernatant was stored at $-20^{\circ} \mathrm{C}$. Salivary IL- 6 was measured using a salivary IL-6 commercial ELISA kit (1-3602, Salimetrics, USA).

2.4. Statistical Analysis. The statistical analysis was done by the SPSS software, version 20 (SPSS, Chicago, IL, USA). To test the normality of data distribution, we used the Shapiro-Wilk test. For nonparametric quantitative data, differences between groups were assessed by Mann-Whitney $U$ -test. For qualitative variables, testing significant differences was done by the chi-square test. Receiver operating characteristic (ROC) analysis was used to determine sensitivity, specificity, and optimal serum and salivary IL-6 cutoff values. A logistic regression model for each combination of biomarkers was performed with the late-onset neonatal pneumonia as the outcome. The predicted values of the logistic regression models were used to test for the predictive performance of the biomarker combination using ROC analysis. Significance is considered at $P$ value of $<0.05$.

\section{Results}

3.1. Demographic Data. Thirty-five cases and 35 controls were included in the study. Males constitute $57.1 \%$ and $65.7 \%$ of cases and controls, respectively, with no statistically significant difference. The mean ages \pm SD of cases and controls were $18 \pm 6.9$ and $19 \pm 7.6$ days, respectively, with no statistically significant difference. There were also no statistically significant differences between both groups $(P$ value $>$ $0.05)$ regarding gestational age, weight, mode of delivery, history of premature rapture of membrane (PROM), and maternal fever.

3.2. Clinical Data. Tachypnea and cough were the most significant presenting symptoms, $30(85.7 \%)$ and $26(74.3 \%)$, respectively, followed by fever $23(65.7 \%)$. In chest examination, fine crepitation was found in 32 (91.4\%), while diminished air entry was found in $24(74.3 \%)$ and chest retraction in $25(71.4 \%)$. Pneumonic patches and air bronchogram in chest X-ray were found in 24 cases $(68.6 \%)$, and interstitial pneumonia was found in 11 cases $(31.4 \%)$. Cases received oxygen support through the nasal cannula, nCPAP, and mechanical ventilation which were $16(45.6 \%), 5(14 \%)$, and 14 (40\%), respectively, (Table 1).

3.3. Laboratory Data Findings. Total leukocytic count (TLC), platelet count, MPV, CRP, CRP/MPV ratio, and salivary and serum IL-6 values showed significant difference between the two groups. The pneumonia group showed higher TLC count and lower platelet count compared to the control group. CRP was significantly higher in the pneumonia group than the control group (mean $37.48 \pm 32.72$ and $3.29 \pm$ $2.50 \mathrm{mg} / \mathrm{l}$, respectively, $P<0.001)$. MPV was significantly different in the two groups $(11.16 \pm 1.49$ and $9.77 \pm 1.51 \mathrm{fl}$ for cases and controls, respectively, $P<0.001)$. In the same context, the CRP/MPV ratio was significantly higher in cases 
TABle 1: Clinical data, examination, and chest X-ray findings.

\begin{tabular}{|c|c|c|c|c|c|}
\hline \multirow{3}{*}{ Tachypnea } & \multicolumn{2}{|c|}{ Pneumonia $(n=35)$} & \multicolumn{2}{|c|}{ Control $(n=35)$} & \multirow{2}{*}{$P$ value } \\
\hline & \multirow[t]{2}{*}{ No. } & \multirow[t]{2}{*}{$\%$} & \multirow[t]{2}{*}{ No. } & \multirow[t]{2}{*}{$\%$} & \\
\hline & & & & & \multirow{4}{*}{$<0.001^{*}$} \\
\hline Absent & 5 & 14.3 & 35 & 100.0 & \\
\hline Present & \multirow[t]{2}{*}{30} & \multirow[t]{2}{*}{85.7} & \multirow[t]{2}{*}{0} & \multirow[t]{2}{*}{0.0} & \\
\hline Cough & & & & & \\
\hline Absent & 9 & 25.7 & 35 & 100.0 & \multirow{2}{*}{$<0.001^{*}$} \\
\hline Present & \multirow[t]{2}{*}{26} & \multirow[t]{2}{*}{74.3} & \multirow[t]{2}{*}{0} & \multirow[t]{2}{*}{0.0} & \\
\hline Fever & & & & & \\
\hline Absent & 12 & 34.3 & 35 & 100.0 & \multirow{3}{*}{$<0.001^{*}$} \\
\hline Present & \multirow[t]{2}{*}{23} & \multirow[t]{2}{*}{65.7} & \multirow[t]{2}{*}{0} & \multirow[t]{2}{*}{0.0} & \\
\hline Retraction & & & & & \\
\hline Absent & 10 & 28.6 & 35 & 100.0 & \multirow{3}{*}{$<0.001^{*}$} \\
\hline Present & \multirow[t]{2}{*}{25} & \multirow[t]{2}{*}{71.4} & \multirow[t]{2}{*}{0} & \multirow[t]{2}{*}{0.0} & \\
\hline Air entry & & & & & \\
\hline Normal & 11 & 25.7 & 35 & 100.0 & \multirow{3}{*}{$<0.001^{*}$} \\
\hline Diminished & \multirow[t]{2}{*}{24} & 74.3 & 0 & 0.0 & \\
\hline Oxygen supply & & & & & \\
\hline Room air & 0 & 0.0 & 35 & 100 & \\
\hline Nasal cannula & 16 & 45.7 & 0.0 & 0.0 & $<0.001^{*}$ \\
\hline nCPAP & 5 & 14.3 & 0.0 & 0.0 & \\
\hline Mechanical ventilation & 14 & 40 & 0.0 & 0.0 & \\
\hline CXR & & & & & \\
\hline Normal & 0 & 0.0 & & & \\
\hline Pneumonic patches & 24 & 68.6 & & & \\
\hline Interstitial pneumonia & 11 & 31.4 & & & \\
\hline
\end{tabular}

nCPAP: nasal continuous positive airway pressure; CXR: chest X-ray; ${ }^{*}$ indicates $P<0.05$.

than controls (mean $3.27 \pm 2.52$ and $0.36 \pm 0.3$, respectively, $P<0.001)$. Salivary IL-6 values were significantly different between the two groups (mean $140.37 \pm 130.97$ and $9.61 \pm$ $13.72 \mathrm{pg} / \mathrm{ml}$ for cases and controls, respectively, $P<0.001)$. Serum IL-6 values showed also a significant difference between the groups (mean 167.86 \pm 154.29 and $10.12 \pm$ $11.10 \mathrm{pg} / \mathrm{ml}$ for cases and controls, respectively, $P<0.001$ ) (Table 2).

3.4. Receiver Operating Characteristic (ROC) Analysis of the Tested Markers and Combination of Markers for the Diagnosis of Late-Onset Neonatal Pneumonia. The ROC curve analysis for salivary and serum IL-6, MPV, and CRP/MPV ratio and for the combination of MPV with salivary and serum IL- 6 and combination of CRP/MPV with salivary and serum IL-6 to detect late-onset neonatal pneumonia are shown in Figure 1.

For salivary IL-6, sensitivity was $82.86 \%$ and specificity was $91.43 \%$, at a cutoff of $34 \mathrm{pg} / \mathrm{ml}$. Serum IL-6 had a sensitivity and specificity of $88.5 \%$ at a cutoff of $15.3 \mathrm{pg} / \mathrm{ml}$. MPV showed a sensitivity and specificity of $85.71 \%$ and $68.57 \%$, respectively, at a cutoff value $9.7 \mathrm{fl}$. The $\mathrm{CRP} / \mathrm{MPV}$ ratio showed a sensitivity and specificity of $97.14 \%$ and $85.71 \%$, respectively, at a cutoff value 0.88 (Table 3 ). When combinations of different markers were used in the analysis, the diagnostic sensitivity and specificity were improved. We found that combining salivary or serum IL-6 with the CRP/MPV ratio markedly increased the sensitivity, specificity, PPV, and NPV to $100 \%$ (Table 4).

\section{Discussion}

Neonatal infection, including pneumonia, is one of the main causes of neonatal death worldwide with an estimation of responsibility of $23.4 \%$ of neonatal mortality each year [37]. Neonatal pneumonia is characterized by nonspecific clinical manifestations that are in common with other respiratory diseases which make it difficult to be identified and treated.

Saliva, as a biofluid, contains many of the same molecules present in the systemic circulation. Moreover, the concentration of most of the molecules present in the saliva is affected directly by their blood concentration. This makes saliva as a potentially useful diagnostic biofluid for disease detection and monitoring in neonates. Saliva has been studied as an alternative biological fluid suitable for a noninvasive diagnostic and follow-up tool in neonatal infections including salivary CRP in the diagnosis of neonatal sepsis and pneumonia $[19,20,38-41]$ and screening of neonatal cytomegalovirus by salivary real-time PCR [42].

IL-6 is an early, highly sensitive proinflammatory cytokine and is one of the most widely studied cytokines in 
TABLE 2: Laboratory data in pneumonia and control groups.

\begin{tabular}{|c|c|c|c|}
\hline & Pneumonia $(n=35)$ mean $\pm S D$ & Control $(n=35)$ mean $\pm S D$ & $P$ value \\
\hline Total leucocyte count $\left(/ \mathrm{mm}^{3}\right)$ & $14.12 \pm 6.56$ & $8.91 \pm 2.22$ & $<0.001^{*}$ \\
\hline Platelet count $\left(10^{3} / \mathrm{mm}^{3}\right)$ & $172.83 \pm 138.27$ & $348.91 \pm 131.54$ & $<0.001^{*}$ \\
\hline $\operatorname{MPV}(\mathrm{fl})$ & $11.16 \pm 1.49$ & $9.77 \pm 1.51$ & $<0.001^{*}$ \\
\hline CRP $(\mathrm{mg} / \mathrm{l})$ & $37.48 \pm 32.72$ & $3.29 \pm 2.50$ & $<0.001^{*}$ \\
\hline $\mathrm{CRP} / \mathrm{MPV}$ ratio & $3.27 \pm 2.52$ & $0.36 \pm 0.30$ & $<0.001^{*}$ \\
\hline Salivary IL-6 (pg/ml) & $140.37 \pm 130.97$ & $9.61 \pm 13.72$ & $<0.001^{*}$ \\
\hline Serum IL-6 (pg/ml) & $167.86 \pm 154.29$ & $10.12 \pm 11.10$ & $<0.001^{*}$ \\
\hline
\end{tabular}

MPV: mean platelet volume; CRP: C-reactive protein; IL-6: interleukin-6.

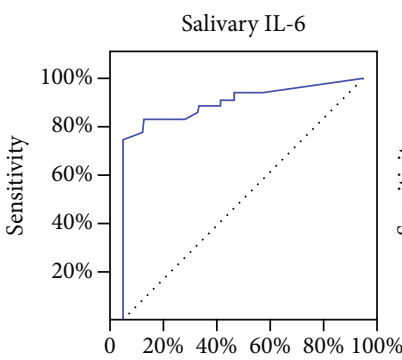

100- Specificity

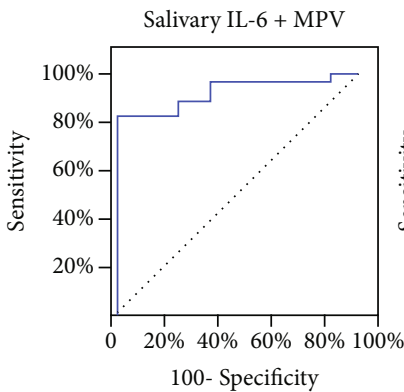

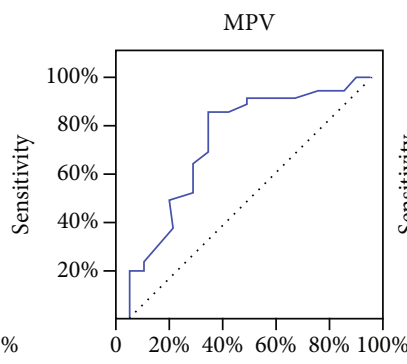

100- Specificity

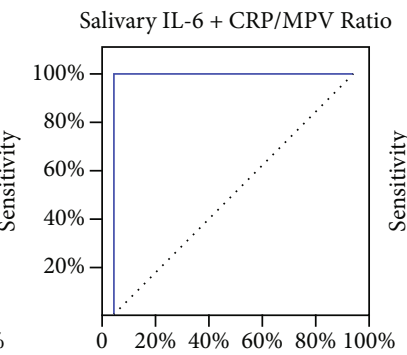

100- Specificity

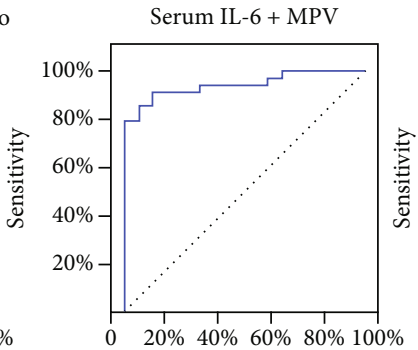

100- Specificity

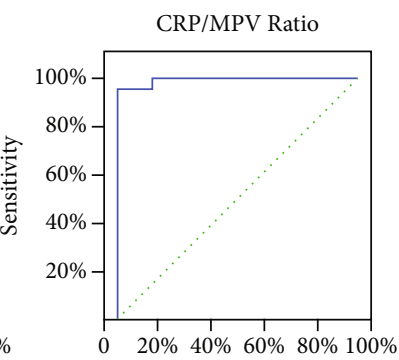

100- Specificity

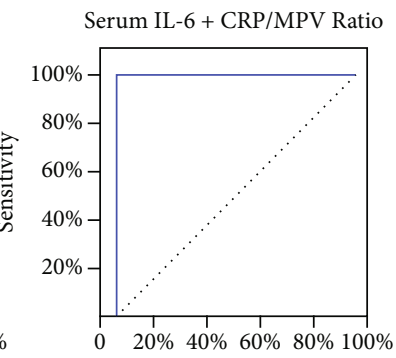

100- Specificity

Figure 1: Receiver operator characteristics for the tested markers and their combination.

TABLE 3: Diagnostic performance of the tested markers for detection of late-onset neonatal pneumonia.

\begin{tabular}{|c|c|c|c|c|c|c|c|}
\hline Parameter & AUC & $95 \% \mathrm{CI}$ & Cutoff value & Sensitivity (\%) & Specificity (\%) & PPV (\%) & NPV (\%) \\
\hline Salivary IL-6 (pg/ml) & 0.907 & $0.833-0.981$ & $>34$ & 82.86 & 91.43 & 90.6 & 84.2 \\
\hline Serum IL-6 (pg/ml) & 0.921 & $0.848-0.993$ & $>15.3$ & 88.57 & 88.57 & 88.6 & 88.6 \\
\hline $\operatorname{MPV}(\mathrm{fl})$ & 0.756 & $0.641-0.872$ & $>9.7$ & 85.71 & 68.57 & 73.2 & 82.8 \\
\hline CRP/MPV ratio & 0.995 & $0.990-1.0$ & $>0.88$ & 97.14 & 85.71 & 87.2 & 96.8 \\
\hline
\end{tabular}

IL-6: interleukin-6; MPV: mean platelet volume; CRP: C-reactive protein.

TABLE 4: Diagnostic performance of the tested marker combination for detection of late-onset neonatal pneumonia.

\begin{tabular}{|c|c|c|c|c|c|c|}
\hline Parameter & AUC & $95 \% \mathrm{CI}$ & Sensitivity (\%) & Specificity (\%) & PPV (\%) & NPV (\%) \\
\hline Salivary IL-6+ MPV & 0.951 & $0.921-0.981$ & 82.86 & 94.29 & 93.55 & 84.62 \\
\hline Salivary IL-6+ CRP/MPV & 1.0 & $1.0-1.0$ & 100 & 100 & 100 & 100 \\
\hline Serum IL-6+ MPV & 0.952 & $0.928-0.976$ & 82.86 & 94.29 & 93.55 & 84.62 \\
\hline Serum IL-6+ CRP/MPV & 1.0 & $1.0-1.0$ & 100 & 100 & 100 & 100 \\
\hline
\end{tabular}

IL-6: interleukin-6; MPV: mean platelet volume; CRP: C-reactive protein. 
neonatal infections [9, 43-45]. IL-6 has a significant role in the early host response to infection, and its blood level changes precede that of CRP, which makes IL-6 an excellent parameter for the monitoring of neonatal sepsis [12].

In this study, the mean serum level of IL- 6 was 167.86 $\pm 154.29 \mathrm{pg} / \mathrm{ml}$ in the case group, with sensitivity and specificity of $88.57 \%$ and $88.57 \%$, respectively, at a cutoff value of $15.3 \mathrm{pg} / \mathrm{ml}$ for the detection of late-onset neonatal pneumonia. A previous cutoff value of $24.65 \mathrm{pg} / \mathrm{ml}$ for serum IL-6 was reported to detect neonatal sepsis with $72 \%$ sensitivity, $84 \%$ specificity, 95\% PPV, and $42 \%$ NPV [21]. Other studies reported a wide range of different serum IL-6 cutoff levels $(10-500 \mathrm{pg} / \mathrm{ml})$. However, most of the reported cutoffs for the detection of neonatal sepsis fall between 10 and $30 \mathrm{pg} / \mathrm{ml}$, which is in agreement with our results [46-48]. Qiu et al. investigated in their meta-analysis the diagnostic value of serum IL-6 as an early biomarker for neonatal sepsis with PROM. Their estimated sensitivity and specificity of serum IL-6 for the detection of neonatal sepsis with PROM were $87 \%$ and $88 \%$, respectively, which was very close to our findings [11].

It was found that the serum IL-6 level had the highest efficacy for identifying bacterial pneumonia in children. It has $100 \%$ sensitivity and $99.14 \%$ specificity in discriminating bacterial pneumonia from viral and atypical pneumonia [49]. In addition, high IL-6 blood level is associated with increased mortality in less than 5-year-old patients with pneumonia requiring mechanical ventilation [50]. Moreover, in pediatric patient's community-acquired pneumonia, higher concentrations of circulating IL- 6 has been correlated with worse outcomes and associated with early mortality [16].

Salivary biomarkers can be highly informative, especially in the early detection and discrimination of a variety of diseases and conditions in neonates, children, and adults [22, 51-54]. Salivary cytokines were detected within the first few hours after birth, and their levels decreased after 3 months [55]. Furthermore, salivary cytokines are promising potential biomarkers of bacterial infection in premature neonates [18].

To our knowledge, this is the first study to investigate the diagnostic value of salivary IL- 6 as a noninvasive biomarker to detect late-onset pneumonia in full-term neonates. Salivary IL-6 values were found to be significantly higher in the case group compared to the control group $(P<0.001)$. Furthermore, we report a sensitivity of $82.86 \%$ and a specificity of $91.43 \%$ at cutoff point $>34 \mathrm{pg} / \mathrm{ml}$ of salivary IL-6. In a recent report, salivary IL-6 levels could predict bacterial infection in premature neonates with high sensitivity and specificity [18]. Klein et al. in 2104 reported that salivary analysis is a potentially useful diagnostic tool for pneumonia in the pediatric age group [56]. Very recently, Tsai and colleagues reported that salivary IL-6 and CRP levels are significantly higher in pediatric patients with pneumonia compared to healthy controls [22].

In our study, we investigated also for the first time the diagnostic value of the CRP/MPV ratio for the detection of late-onset neonatal pneumonia in full-term neonates. Here, we report a high ability of the CRP/MPV ratio to detect dis- eased neonates with sensitivity $97.14 \%$ and specificity of $85.71 \%$ at a cutoff value $>0.88$. In children, the CRP/MPV ratio might be used in differentiating bacterial from viral pneumonia and prediction of complications [33].

The perfect diagnostic biomarker is a marker of approximately $100 \%$ sensitivity and $100 \%$ NPV. This can be attained by combining different markers for the diagnosis of neonatal infections including late-onset neonatal pneumonia. In this study, we found that combining of either serum or salivary IL- 6 with the CRP/MPV ratio could detect neonatal pneumonia more effectively than each marker alone with $100 \%$ sensitivity and $100 \%$ NPV. Some previous studies investigated the diagnostic value of simultaneous combinations of several biomarkers in the diagnosis of neonatal infections. Combining CRP with IL-6 was more useful for the early detection of neonatal sepsis compared to each marker alone $[4,21]$. Also, Zeitoun et al. showed that combining IL-10 with nCD64 improved the sensitivity and NPV for detecting of neonatal sepsis [57].

The main limitations of the current study are the small sample size and neonates with late-onset sepsis were only included.

\section{Conclusion}

This is the first study to report significantly higher salivary IL-6 and CRP/MPV ratio in neonates with late-onset pneumonia compared to controls. Combination of CRP/MPV with serum and salivary IL-6 improved the diagnostic accuracy of late-onset neonatal pneumonia in full-term neonates. Salivary IL-6 could be used as a potential noninvasive marker for the diagnosis of full-term neonates with lateonset neonatal pneumonia.

\section{Data Availability}

The data used to support the findings of this study are included within the article.

\section{Conflicts of Interest}

The authors declare no conflict of interest.

\section{Authors' Contributions}

A.O. has substantially contributed to the conception and design of the study; acquisition, analysis, and interpretation of the data; drafting the paper; and supervising the whole work. Y.A. has substantially contributed to the acquisition, analysis, and interpretation of the data. M.O. performed the laboratory part of this study, substantially contributed to interpretation of the data, and revised the article critically for important intellectual content. A.K. and A.R.R. have substantially contributed to the conception and design of the study and acquisition and interpretation of the data and revised the article critically for important intellectual content. S.E. has substantially contributed to the conception and design of the study and interpretation of the data, revised the article critically for important intellectual 
content, and supervised the whole work. Ahmed Omran and Yasmin Ali contributed equally to this work.

\section{References}

[1] M. D. Nissen, "Congenital and neonatal pneumonia," Paediatric Respiratory Reviews, vol. 8, no. 3, pp. 195-203, 2007.

[2] M. Mihara, M. Hashizume, H. Yoshida, M. Suzuki, and M. Shiina, "IL-6/IL-6 receptor system and its role in physiological and pathological conditions," Clinical Science, vol. 122, no. 4, pp. 143-159, 2012.

[3] C. U. Ebenebe, F. Hesse, M. E. Blohm, R. Jung, S. Kunzmann, and D. Singer, "Diagnostic accuracy of interleukin-6 for earlyonset sepsis in preterm neonates," The Journal of MaternalFetal \& Neonatal Medicine, vol. 34, no. 2, pp. 253-258, 2021.

[4] I. Berka, P. Korček, and Z. Straňák, "C-reactive protein, interleukin-6, and procalcitonin in diagnosis of late-onset bloodstream infection in very preterm infants," Journal of the Pediatric Infectious Diseases Society, 2021.

[5] J. S. Cortés, P. X. Losada, L. X. Fernández et al., "Interleukin-6 as a biomarker of early-onset neonatal sepsis," American Journal of Perinatology, vol. 38, no. S 01, pp. e338-e346, 2021.

[6] E. A. Morad, R. A. Rabie, M. A. Almalky, and M. G. Gebriel, "Evaluation of procalcitonin, C-reactive protein, and interleukin-6 as early markers for diagnosis of neonatal sepsis," International Journal of Microbiology, vol. 2020, Article ID 8889086, 9 pages, 2020.

[7] B. Tessema, N. Lippmann, A. Willenberg, M. Knüpfer, U. Sack, and B. König, "The diagnostic performance of interleukin-6 and C-reactive protein for early identification of neonatal sepsis," Diagnostics, vol. 10, no. 11, p. 978, 2020.

[8] C. Liu, C. Fang, Q. He, and L. Xie, "The value of interleukin-6 (IL-6) within 6 hours after birth in the prompt diagnosis of early-onset neonatal sepsis," Translational Pediatrics, vol. 9, no. 5, pp. 629-635, 2020.

[9] P. C. Ng and H. S. Lam, "Biomarkers for late-onset neonatal sepsis: cytokines and beyond," Clinics in Perinatology, vol. 37, no. 3, pp. 599-610, 2010.

[10] A. Prashant, P. Vishwanath, P. Kulkarni et al., "Comparative assessment of cytokines and other inflammatory markers for the early diagnosis of neonatal sepsis-a case control study," PLoS One, vol. 8, no. 7, article e68426, 2013.

[11] X. Qiu, L. Zhang, Y. Tong, Y. Qu, H. Wang, and D. Mu, “Interleukin-6 for early diagnosis of neonatal sepsis with premature rupture of the membranes: a meta-analysis," Medicine, vol. 97, no. 47 , p. e13146, 2018.

[12] Q. Ye, L. Z. du, W. X. Shao, and S. Q. Shang, "Utility of cytokines to predict neonatal sepsis," Pediatric Research, vol. 81, no. 4, pp. 616-621, 2017.

[13] Y.-L. Lee, W. Chen, L. Y. Chen et al., "Systemic and bronchoalveolar cytokines as predictors of in-hospital mortality in severe community-acquired pneumonia," Journal of Critical Care, vol. 25, no. 1, pp. 176.e7-176.e13, 2010.

[14] C. Monton and A. Torres, "Lung inflammatory response in pneumonia," Monaldi archives for chest disease $=$ Archivio Monaldi per le malattie del torace, vol. 53, no. 1, pp. 56-63, 1998.

[15] G. Antunes, S. A. Evans, J. L. Lordan, and A. J. Frew, "Systemic cytokine levels in community-acquired pneumonia and their association with disease severity," European Respiratory Journal, vol. 20, no. 4, pp. 990-995, 2002.
[16] M. Bacci, R. C. P. Leme, N. P. C. Zing et al., "IL-6 and TNF- $\alpha$ serum levels are associated with early death in communityacquired pneumonia patients," Brazilian Journal of Medical and Biological Research, vol. 48, no. 5, pp. 427-432, 2015.

[17] R. C. C. M. de Brito, N. Lucena-Silva, L. C. Torres, C. F. Luna, J. B. Correia, and G. A. P. da Silva, "The balance between the serum levels of IL- 6 and IL-10 cytokines discriminates mild and severe acute pneumonia," BMC Pulmonary Medicine, vol. 16, no. 1, pp. 1-10, 2016.

[18] I.-L. Chen, H. C. Huang, M. C. Ou-Yang, F. S. Chen, M. Y. Chung, and C. C. Chen, "A novel method to detect bacterial infection in premature infants: using a combination of inflammatory markers in blood and saliva," Journal of Microbiology, Immunology and Infection, vol. 53, no. 6, pp. 892-899, 2020.

[19] A. Omran, M. Ali, M. H. S. Mohammad, and O. Zekry, "Salivary $\mathrm{C}$-reactive protein and mean platelet volume in diagnosis of late-onset neonatal pneumonia," The Clinical Respiratory Journal, vol. 12, no. 4, pp. 1644-1650, 2018.

[20] A. Omran, A. Maaroof, M. H. S. Mohammad, and A. Abdelwahab, "Proteina $\mathrm{C}$ reativa salivar, volume medio de plaquetas e proporçao de neutrofilos/linfocitos como marcadores de diagnostico de sepse neonatal," Jornal de Pediatria, vol. 94, no. 1, pp. 82-87, 2018.

[21] I. H. Celik, F. G. Demirel, N. Uras et al., "What are the cut-off levels for IL-6 and CRP in neonatal sepsis?," Journal of Clinical Laboratory Analysis, vol. 24, no. 6, pp. 407-412, 2010.

[22] C. M. Tsai, K. S. Tang, M. C. Cheng et al., "Use of saliva sample to detect C-reactive protein in children with pneumonia," Pediatric Pulmonology, vol. 55, no. 9, pp. 2457-2462, 2020.

[23] B. Karabulut and S. O. Alatas, "Diagnostic value of neutrophil to lymphocyte ratio and mean platelet volume on early onset neonatal sepsis on term neonate," Journal of Pediatric Intensive Care, vol. 10, no. 2, pp. 143-147, 2021.

[24] G.-P. Milas, V. Karageorgiou, and I. Bellos, "Mean platelet volume and neonatal sepsis: a systematic review and metaanalysis of diagnostic accuracy," The Journal of MaternalFetal \& Neonatal Medicine, pp. 1-13, 2021.

[25] G. Aktas, A. Alcelik, B. K. Tekce, V. Tekelioglu, M. Sit, and H. Savli, "Red cell distribution width and mean platelet volume in patients with irritable bowel syndrome," Przeglad Gastroenterologiczny, vol. 3, pp. 160-163, 2014.

[26] S. Bilgin, G. Aktas, G. Kahveci, B. M. Atak, O. Kurtkulagi, and T. T. Duman, "Does mean platelet volume/lymphocyte count ratio associate with frailty in type 2 diabetes mellitus?," Bratislavské Lekárske Listy, vol. 122, no. 2, pp. 116-119, 2021.

[27] I. Karagoz, G. Aktas, H. Yoldas et al., "Association between hemogram parameters and survival of critically ill patients," Journal of Intensive Care Medicine, vol. 34, no. 6, pp. 511-513, 2019.

[28] M. Zahid Kocak, G. Aktas, E. Erkus, T. T Duman, B. M Atak, and H. Savli, "Mean platelet volume to lymphocyte ratio as a novel marker for diabetic nephropathy," Journal of the College of Physicians and Surgeons-Pakistan, vol. 28, no. 11, pp. 844-847, 2018.

[29] I. Sincer, Y. Gunes, A. K. Mansiroglu, M. Cosgun, and G. Aktas, "Association of mean platelet volume and red blood cell distribution width with coronary collateral development in stable coronary artery disease," Postępy w Kardiologii Interwencyjnej= Advances in Interventional Cardiology, vol. 14, no. 3, pp. 263-269, 2018.

[30] M. Sit, G. Aktas, B. Ozer et al., "Mean platelet volume: an overlooked herald of malignant thyroid nodules," Acta Clinica Croatica, vol. 58, no. 3, pp. 417-420, 2019. 
[31] M. Sit, G. Aktaş, E. E. Yilmaz, İ. N. Hakyemez, A. Alçelik, and A. Küçükbayrak, "Platelet parameters in hepatic hydatid cysts," International Journal of Inflammation, vol. 2013, Article ID 593273, 3 pages, 2013.

[32] G. Aktaş, M. Sit, H. Tekce et al., "Mean platelet volume in nasal polyps," The West Indian Medical Journal, vol. 62, no. 6, p. $515,2013$.

[33] M. Bekdas, S. B. Goksugur, E. G. Sarac, M. Erkocoglu, and F. Demircioglu, "Neutrophil/lymphocyte and C-reactive protein/mean platelet volume ratios in differentiating between viral and bacterial pneumonias and diagnosing early complications in children," Saudi Medical Journal, vol. 35, no. 5, pp. 442-447, 2014.

[34] E. D. Barnett and J. O. Klein, "Bacterial infections of the respiratory tract," in Infectious Diseases of the Fetus and Newborn, pp. 276-296, Elsevier, 2011.

[35] F. Chiappelli, F. J. I. Iribarren, and P. Prolo, "Salivary biomarkers in psychobiological medicine," Bioinformation, vol. 1, no. 8, pp. 331-334, 2006.

[36] J. A. Dietz, K. L. Johnson, H. C. Wick, D. W. Bianchi, and J. L. Maron, "Optimal techniques for mRNA extraction from neonatal salivary supernatant," Neonatology, vol. 101, no. 1, pp. 55-60, 2012.

[37] G. J. Chan, A. C. C. Lee, A. H. Baqui, J. Tan, and R. E. Black, "Risk of early-onset neonatal infection with maternal infection or colonization: a global systematic review and meta-analysis," PLoS Medicine, vol. 10, no. 8, article e1001502, 2013.

[38] S. Datla, S. Kitchanan, and G. Sethuraman, "Diagnostic reliability of salivary C-reactive protein as an alternative noninvasive biomarker of neonatal sepsis," Indian Pediatrics, vol. 58, no. 8, pp. 745-748, 2021.

[39] A. Iyengar and J. L. Maron, "Detecting infection in neonates: promises and challenges of a salivary approach," Clinical Therapeutics, vol. 37, no. 3, pp. 523-528, 2015.

[40] A. Iyengar, J. K. Paulus, D. J. Gerlanc, and J. L. Maron, “Detection and potential utility of C-reactive protein in saliva of neonates," Frontiers in Pediatrics, vol. 2, p. 131, 2014.

[41] A. M. Tosson, D. Koptan, R. Abdel Aal, and M. Abd Elhady, "Evaluation of serum and salivary C-reactive protein for diagnosis of late- onset neonatal sepsis: a single center crosssectional study," Jornal de Pediatria, 2021.

[42] S. B. Boppana, S. A. Ross, M. Shimamura et al., "Saliva polymerase-chain-reaction assay for cytomegalovirus screening in newborns," New England Journal of Medicine, vol. 364, no. 22, pp. 2111-2118, 2011.

[43] M. Cernada, N. Badía, V. Modesto et al., "Cord blood interleukin-6 as a predictor of early-onset neonatal sepsis," Acta Paediatrica, vol. 101, no. 5, pp. e203-e207, 2012.

[44] T. Cobo, M. Kacerovsky, C. Andrys et al., "Umbilical cord blood IL-6 as predictor of early-onset neonatal sepsis in women with preterm prelabour rupture of membranes," PLoS One, vol. 8, no. 7, article e69341, 2013.

[45] M. A. C. Rego, F. Eulógio Martinez, J. Elias, and M. M. MussiPinhata, "Diagnostic value of interleukin-6 and C-reactive protein on early onset bacterial infection in preterm neonates with respiratory distress," Journal of Perinatal Medicine, vol. 38, no. 5, pp. 527-533, 2010.

[46] S. Mehr and L. W. Doyle, "Cytokines as markers of bacterial sepsis in newborn infants: a review," The Pediatric Infectious Disease Journal, vol. 19, no. 9, pp. 879-887, 2000.
[47] P. Ng, S. H. Cheng, K. M. Chui et al., "Diagnosis of late onset neonatal sepsis with cytokines, adhesion molecule, and Creactive protein in preterm very low birthweight infants," Archives of Disease in Childhood. Fetal and Neonatal Edition, vol. 77, no. 3, pp. F221-F227, 1997.

[48] E. E. Önal, F. Kitapçi, U. Dilmen, and B. Adam, "Interleukin-6 concentrations in neonatal sepsis," The Lancet, vol. 353, no. 9148, pp. 239-240, 1999.

[49] J.-M. Zhou and Q. Ye, "Utility of assessing cytokine levels for the differential diagnosis of pneumonia in a pediatric population," Pediatric Critical Care Medicine, vol. 18, no. 4, pp. e162-e166, 2017.

[50] T. Nguyen Thi Dieu, A. Pham Nhat, T. J. Craig, and S. DuongQuy, "Clinical characteristics and cytokine changes in children with pneumonia requiring mechanical ventilation," Journal of International Medical Research, vol. 45, no. 6, pp. 1805-1817, 2017.

[51] H. al Suwaidi, A. Senok, R. Varghese et al., "Saliva for molecular detection of SARS-CoV-2 in school-age children," Clinical Microbiology and Infection, vol. 27, no. 9, pp. 1330-1335, 2021.

[52] E. M. de Koff, S. M. Euser, P. Badoux et al., "Respiratory pathogen detection in children: saliva as a diagnostic specimen," The Pediatric Infectious Disease Journal, vol. 40, no. 9, pp. e351-e353, 2021.

[53] M. Huber, P. W. Schreiber, T. Scheier et al., "High efficacy of saliva in detecting SARS-CoV-2 by RT-PCR in adults and children," Microorganisms, vol. 9, no. 3, p. 642, 2021.

[54] R. Yee, T. T. Truong, P. S. Pannaraj et al., "Saliva is a promising alternative specimen for the detection of SARS-CoV-2 in children and adults," Journal of Clinical Microbiology, vol. 59, no. 2, article e02686, 2021.

[55] M. L. T. Sesso, M. C. L. Borges, V. P. L. Ferriani, V. R. GeraldoMartins, D. B. R. Rodrigues, and R. D. Nogueira, "Prospective evaluation of cytokine in saliva of preterm and fullterm neonates," Immunobiology, vol. 219, no. 11, pp. 830-835, 2014.

[56] A. Klein Kremer, E. Kuzminsky, L. Bentur, and R. M. Nagler, "Salivary and serum analysis in children diagnosed with pneumonia," Pediatric Pulmonology, vol. 49, no. 6, pp. 569-573, 2014.

[57] A. A. Zeitoun, S. S. Gad, F. M. Attia, A. S. Abu Maziad, and E. F. Bell, "Evaluation of neutrophilic CD64, interleukin 10 and procalcitonin as diagnostic markers of early- and lateonset neonatal sepsis," Scandinavian Journal of Infectious Diseases, vol. 42, no. 4, pp. 299-305, 2010. 